Canadian

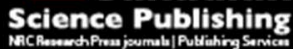

Applied Physiology, Nutrition, and Metabolism Physiologie appliquée, nutrition et métabolisme

\title{
The effect of dairy products consumed with high glycemic carbohydrate on subjective appetite, food intake and post- prandial glycemia in older adults
}

\begin{tabular}{|r|l|}
\hline Journal: & Applied Physiology, Nutrition, and Metabolism \\
\hline Manuscript ID & apnm-2017-0210.R1 \\
\hline Manuscript Type: & Article \\
\hline Date Submitted by the Author: & 15 -Jun-2017 \\
\hline Complete List of Authors: & $\begin{array}{l}\text { Law, Marron; University of Toronto Faculty of Medicine, Nutritional } \\
\text { Sciences } \\
\text { Lee, Ying Ti; University of Toronto Faculty of Medicine, Nutritional Sciences } \\
\text { Vien, Shirley; University of Toronto Faculty of Medicine, Nutritional } \\
\text { Sciences } \\
\text { Luhovyy, Bohdan; Mount Saint Vincent Univeristy, Applied Human Nutrition } \\
\text { Anderson, G. Harvey; University of Toronto, Nutritional Sciences }\end{array}$ \\
\hline $\begin{array}{r}\text { Is the invited manuscript for } \\
\text { consideration in a Special } \\
\text { Issue? : }\end{array}$ & \\
\hline Keyword: & dairy, satiety, appetite, food intake, glycemia \\
\hline \hline
\end{tabular}


The effect of dairy products consumed with high glycemic carbohydrate on subjective appetite, food intake and post-prandial glycemia in older adults

Marron Law ${ }^{1}$, Ying Ti Lee ${ }^{1}$, Shirley Vien ${ }^{1}$, Bohdan L. Luhovyy ${ }^{2}$, G. Harvey Anderson ${ }^{3}$

Corresponding author: G. Harvey Anderson, Ph.D., Department of Nutritional Sciences, Faculty of Medicine, University of Toronto, 150 College Street, Toronto ON, Canada, M5S 3E2

Tel: (416) 978-1832; Email: harvey.anderson@utoronto.ca

${ }^{1}$ Department of Nutritional Sciences, Faculty of Medicine, University of Toronto, Toronto, ON, Canada M5S 3E2; ${ }^{2}$ Department of Applied Human Nutrition, Mount Saint Vincent University, Halifax, NS, Canada B3M 2J6; ${ }^{3}$ Department of Nutritional Sciences and Physiology, Faculty of Medicine, University of Toronto, Toronto, ON, Canada M5S 3E2

Marron Law: marron.law@mail.utoronto.ca; Ying Ti Lee: yingti.lee@mail.utoronto.ca; Shirley Vien: shirley.vien@utoronto.ca; Bohdan L. Luhovyy: bohdan.luhovyy@msvu.ca; G. Harvey Anderson: harvey.anderson@utoronto.ca

Clinical trial registry number: https://clinicaltrials.gov NCT02607007. 


\begin{abstract}
Objective: To compare the effect of liquid, semi-solid and solid dairy products and a nondairy beverage when consumed with glycemic carbohydrate on subjective appetite, food intake (FI) and post-prandial glycemia (PPG) in healthy older adults.

Design: Thirty healthy men and women (14 males and 16 females; age: $64.6 \pm 2.4$ y; BMI: $\left.25.6 \pm 2.5 \mathrm{~kg} / \mathrm{m}^{2}\right)$ participated in a randomized crossover study. Treatments were one of 250 $\mathrm{mL}$ of $2 \%$ fat milk and soy beverage, $175 \mathrm{~g}$ of $2 \%$ Greek yogurt and $30 \mathrm{~g}$ of Cheddar cheese consumed as part of an isocaloric (380 kcal) meal with bread and jam. Water alone served as the energy-free control for subjective appetite. At 180 min after consumption, the participants were fed an ad libitum meal to measure FI. Subjective appetite, blood glucose and insulin were measured at baseline and at intervals both before (post-treatment) and after the meal (post-meal).
\end{abstract}

Results: Cheese and yogurt resulted in lower post-treatment blood glucose than milk and soy beverage when consumed with carbohydrate $(p<0.0001)$ but no differences between any treatments were observed post-meal. Treatments led to similar insulin concentrations. Posttreatment appetite was lower than after the water control for all treatments but suppressed more by cheese and yogurt compared to milk $(p<0.0001)$. There were no differences in FI between treatments.

Conclusions: Cheese and yogurt increase satiety and lower PPG more than milk or a soy beverage when consumed with carbohydrate.

Key words: dairy, satiety, appetite, food intake, glycemia 


\section{Introduction}

Foods that increase satiety and decrease PPG may be effective for the prevention and management of obesity and T2D (Pasin and Comerford 2015, Onvani et al. 2016). To encourage development and identification of such foods, Health Canada (HC) released two draft guidance documents for food health claims for "satiety" (Health Canada 2012) and "the reduction in post-prandial glycemic response" (Health Canada 2012, Health Canada 2013). These documents acknowledge the potential acute benefits of increasing satiety and decreasing PPG, however do not allow for claims related to long-term benefits such as implications for control of obesity and T2D. The European Food Safety Authority (EFSA) also released their document related to both claims (European Food Safety Authority 2012). Milk proteins are well-known to increase satiety and reduce FI and PPG (Akhavan et al. 2010, Akhavan et al. 2011, Akhavan et al. 2014). More recently, the focus has shifted to milk as a whole entity. Milk consumed in typical serving sizes (e.g. 250-500 mL) decreases appetite, FI and PPG more than other beverages such as juice and colas (Dove et al. 2009, Maersk et al. 2012, Panahi et al. 2013, Panahi et al. 2013, Mehrabani et al. 2016). Similar results have also been seen with liquid and semi-solid yogurts (Tsuchiya et al. 2006, Almiron-Roig et al. 2009, Chapelot and Payen 2010, El Khoury et al. 2014). Therefore, dairy products are candidates for health claims related to appetite and blood glucose control. However, dairy products vary in macronutrient composition and food form which may be expected to result in different effects.

There has only been one report comparing different dairy forms on appetite and PPG. Isocaloric (201 kcal) amounts of yogurt (278 g), Cheddar cheese (49 g) and semi-skimmed milk (410 mL) containing $10.9 \mathrm{~g}, 12.3 \mathrm{~g}$ and $13.9 \mathrm{~g}$ of protein, respectively, were compared. Yogurt suppressed hunger the most but there were no differences in FI 90 min later or blood 
glucose and insulin measured at 80 min (Dougkas et al. 2012). When skim milk (250 mL, $16.6 \mathrm{~g}$ protein) was compared to three yogurts $(250 \mathrm{~g})$ containing $23.1 \mathrm{~g}, 22.2 \mathrm{~g}$ and $18.3 \mathrm{~g}$ of protein, there were no differences in satiety, FI 120 min later or blood glucose before and after the test meal (El Khoury et al. 2014). However, the effect of dairy consumed at meals with carbohydrate has received little attention even though milk with carbohydrate results in lower blood glucose than carbohydrate alone (Panahi et al. 2013, Sun et al. 2015).

Health claims encouraging consumption of dairy at meals to improve satiety and glycemia may be of specific importance to older adults. Adults post 50 years old have a high prevalence of overweight and obese individuals and are the most at-risk for developing T2D (Kirkman et al. 2012). However, dairy consumption decreases with age (Sebastian et al. 2010, Chollet et al. 2014). In 2004, only 26 and $20 \%$ of Canadian men and women aged 51 to 70 years consumed the recommended amount (Statistics Canada 2006). In addition, non-dairy alternatives have been growing in popularity, competing with milk and contributing to the decline in milk consumption (Government of Canada 2013, Mintel 2016). The effects of these beverages in comparison with dairy when consumed with carbohydrate by this population have not been reported.

Therefore, the objective of this study was to compare the effects of $2 \%$ milk, $2 \%$ Greek yogurt, Cheddar cheese and soy beverage consumed with glycemic carbohydrate on PPG, satiety, as measured by subjective appetite, and FI 180 min later in healthy older men and women. Additionally, a second objective was to determine if a health claim could be made by applying HC's guidance document for comparative satiety claims. We hypothesized that semi-solid and solid dairy products increase satiety, as measured by subjective appetite, and 
decrease FI and PPG more than the liquid dairy product and that all dairy products will be more effective than a non-dairy beverage.

\section{Materials and Methods}

\section{Subjects}

Men and women between the ages of 60-70 years old with a body mass index (BMI) of 18.5$29.9 \mathrm{~kg} / \mathrm{m}^{2}$ were eligible to participate. Participants were recruited through advertisements posted online, around the city of Toronto and newspapers. Exclusion criteria included smokers, breakfast skippers, lactose intolerance and allergies to study foods, dislike of study foods, trying to lose or gain weight, fasting blood glucose of $\geq 6.0 \mathrm{mmol} / \mathrm{L}$, diabetes or any prescription medication or medical conditions that could interfere with study outcomes.

Restrained eaters as identified by a score of $\geq 11$ on the Eating Habits Questionnaire were also excluded (Herman and Polivy 1980). Women that had not undergone menopause for at least one year and who were on hormonal treatments were also excluded. The sample size required for detection of treatment effects of $10 \%$ reduction on subjective appetite over $120 \mathrm{~min}$ and FI at 120 min were 26 and 18 , respectively, and for detection of a $20 \%$ difference in PPG was estimated to be 12 based on previous short-term satiety, FI and glycemia studies with dairy (Panahi et al. 2013, El Khoury et al. 2014). Participants were financially compensated and the study protocol was approved by the Human Subject Review Committee at the University of Toronto Ethics Review Office.

\section{Study Design}

This experiment was a randomized, non-blinded, crossover design. Participants were provided each treatment once per week in random order using a randomized block design generated with a random generator script in SAS version 9.3 (SAS Institute Inc., Cary, NC, USA). Due 
to the obvious differences between treatments, neither study coordinators nor participants could be blinded to the treatments. Treatments were $2 \%$ M.F. milk ( $2 \%$ milk), soy beverage, Cheddar cheese, 2\% Greek yogurt and water (control). Each treatment, except for water, was consumed with bread and jam as part of a breakfast meal. An ad libitum meal was served 180 min following the breakfast meal. Satiety, blood glucose and insulin were measured at baseline and at intervals before and after the ad libitum meal, during which FI was measured.

\section{Treatments}

Treatments were: 1) 2\% milk (Neilson Dairy; St-Laurent, Canada); 2) soy beverage (vanillaflavoured) (So Good; Vancouver, Canada); 3) Cheddar cheese (Armstrong; St-Laurent, Canada); 4) 2\% Greek yogurt (Danone; Boucherville, Canada) and 5) water (control). To equate the volumes of the liquid treatments, water was provided with yogurt and cheese. Each caloric treatment (i.e. excluding water) was part of an isocaloric $(380 \mathrm{kcal})$ breakfast meal that also included two slices (75 g) of white bread (Wonder Bread, Mississauga, Canada) and strawberry jam (Smuckers; Markham, Canada). White Wonder Bread has a GI of 73 and strawberry jam has a GI of 51 both for $30 \mathrm{~g}$ servings when compared to $50 \mathrm{~g}$ of glucose (GI = 100) (Foster-Powell et al. 2002). Water was served alone (without bread or jam) as the energy-free control, as recommended by HC for satiety claims (Health Canada 2012). The breakfast meals were isocaloric to fulfill HC's guidelines stating that the test foods should be of equal or lower energy content than the reference foods. This was achieved by modifying the amount of jam served with each treatment. The serving sizes of the treatments were chosen to represent one serving size as listed on the products' Nutrition Facts Table as recommended by the guidelines. The serving size and nutritional composition of each treatment and breakfast food is outlined in Table 1. 
All treatments were served chilled and the bread was provided toasted and served with the

jam uniformly spread. An additional $100 \mathrm{~mL}$ of water was provided to reduce the aftertaste of the breakfast meal which participants were instructed to drink only when they had finished all the other food and beverages.

\section{Protocol}

Each participant was scheduled to arrive at the same time (between 8:30 and 10 am) and day of the week to the Department of Nutritional Sciences at the University of Toronto for each of their five study sessions. Participants were required to observe a $12 \mathrm{~h}$ overnight fast, except for water, which was permitted until $1 \mathrm{~h}$ before the session. They were also instructed to refrain from vigorous exercise and alcohol consumption the day before their sessions and to eat similarly the evenings before.

Upon arrival, participants completed questionnaires, as described previously (Akhavan and Anderson 2007), to ensure no unusual deviations from their diet and lifestyle patters from the previous day and current morning. If they were deemed unfit to participate (e.g. due to sickness), they were rescheduled. Participants then completed VAS questionnaires to assess their "Food Intake and Activity Level”, "Sleep Habits", "Stress Factors”, "Feelings of Fatigue", "Physical Comfort" and "Motivation to Eat" (Panahi et al. 2013, El Khoury et al. 2014). The "Motivation to Eat" VAS consisted of four appetite questions assessing the participants' "desire to eat" (DTE), "hunger", "fullness" and "prospective food consumption" (PFC). An average appetite score calculated from these four questions as previously described (Patel et al. 2013). 
Participants provided a baseline finger prick capillary blood sample using a single-use lancet (Unistik; Oxfordshire, UK). Plasma blood glucose concentration was measured with a glucometer (Accu-Chek Aviva; Roche Diagnostics Canada, Laval, Canada). A baseline measurement of $\geq 6.0 \mathrm{mmol} / \mathrm{L}$ suggested non-compliance with the fasting instructions or high fasting blood glucose and the participant was rescheduled or excluded from the study.

Participants were instructed to consume the breakfast meal within 10 min while eating at a steady pace. After consumption, the palatability of the treatment was measured by a VAS questionnaire assessing the "pleasantness", "taste", "texture" and "overall liking". An average score calculated from these four questions were used to measure palatability. Subjective appetite and blood glucose were measured at 15, 30, 45, 60, 90, 120, 150 and 180 min (posttreatment period) from the time participants began eating the breakfast meal and insulin was measured at 0 (baseline), 30, 60, 90, 120, 150 and $180 \mathrm{~min}$. Blood for insulin analysis was collected via finger prick (as previous described) with Microvette capillary tubes $300 \mathrm{Z}$ (Sarstedt, Numbrecht, Germany). Blood was then immediately centrifuged $\left(20^{\circ} \mathrm{C}, 10000 \mathrm{rpm}\right.$, $5 \mathrm{~min}$ ) and the plasma were frozen at $-80^{\circ} \mathrm{C}$ until measurements. Insulin levels were quantified with an insulin enzyme-linked immunoabsorbent (ELISA) kit (Alpco, Salem, USA). Participants were asked to remain seated throughout the session and were permitted to do quiet activities such as read or listen to music.

Satiety was measured over $180 \mathrm{~min}(3 \mathrm{~h})$ at which time participants were fed an ad libitum test meal. This is consistent with HC's guidance document for testing the minimum duration of effect for satiety for a health claim. The meal consisted of rice (Uncle Ben's, Bolton, Canada), beef meatballs (President's Choice, Brampton, Canada) and tomato sauce (Ragu, Mount Prospect, USA). The meatballs were cut into small and uniform pieces and were mixed 
homogeneously with the other ingredients in a bowl. One bowl was a $479.5 \mathrm{~g}$ portion which represented $827.5 \mathrm{kcal}, 30.8 \mathrm{~g}$ fat, $104.8 \mathrm{~g}$ carbohydrate and $30.2 \mathrm{~g}$ protein. Participants were allowed 20 min to eat and were instructed to eat until they felt "comfortably full". Halfway through the meal (10 min), their bowl was replaced with a fresh and warm bowl of food.. Subjective appetite, blood glucose and insulin were measured at $210 \mathrm{~min}$ (post-meal period). Test meal consumption was calculated by weighing the amount of food consumed and based on the nutritional information provided by the manufacturers. Ad libitum water intake at the test meal was measured by weight $(\mathrm{g})$.

Cumulative energy intake was calculated by adding the caloric content of the fixed breakfast with the calories consumed at the test meal. Caloric compensation, expressed as a percentage, was calculated using the following formula: Caloric compensation $=[(\mathrm{kcal}$ consumed at the test meal after the water control - kcal consumed at the meal after the treatment $) /(\mathrm{kcal}$ of the treatment)] x 100\%. A caloric compensation of $<100 \%$ indicates undercompensation while a score $>100 \%$ indicates overcompensation (greater reduction) at the test meal for the energy consumed at breakfast (Panahi et al. 2013).

\section{Statistical Analyses}

Statistical analyses were conducted using SAS version 9.3 (SAS Institute Inc., Cary, NC). Two and three-factor repeated-measures analysis of variance (ANOVA; via PROC MIXED procedure) and two-factor repeated-measures analysis of covariance (ANCOVA; via PROC MIXED procedure) were performed to analyze the effects of treatment, time, sex and their interaction on dependent variables over the study period including changes from baseline for subjective appetite scores, blood glucose and insulin concentrations and means for FI, cumulative energy intake, water intake and caloric compensation. Absolute baseline values 
were used as covariates for subjective appetite, blood glucose and insulin. No significant interactions were found between treatment and sex for any of the variables, therefore these results were pooled for both men and women. When there was a significant treatment by time interaction, one-factor ANOVA (PROC MIXED procedure) was followed by Tukey's posthoc test to investigate the effect of treatment on changes from baseline for appetite, blood glucose and insulin at each time of measurement and means for FI, cumulative energy intake, water intake and caloric compensation. Post-treatment changes from baseline were calculated from 15-180 min, post-meal changes at $210 \mathrm{~min}$ and cumulative changes from 15-210 min. Since water was only included as an energy-free control to abide by the guidelines stated in HC's guidance document for satiety and not PPG, it was only included in the analysis for subjective appetite and FI. Total areas under the curve (tAUC) for subjective appetite and incremental areas under the curve (iAUC) were calculated for blood glucose and insulin separately for the post-treatment, post-meal and cumulative periods; post-treatment, post-meal and cumulative periods were 0-180 $\mathrm{min}, 180-210 \mathrm{~min}$, and 0-210 $\mathrm{min}$, respectively, for all variables. Glucose to insulin iAUC ratios were compared among treatments by dividing the blood glucose iAUC by the insulin iAUC for the post-treatment, post-meal and cumulative periods. The glucose to insulin mean changes from baseline ratios at $30 \mathrm{~min}$ were also calculated. Glucose to insulin ratio measures the efficacy of insulin action (Vuguin et al. 2001). The lower the ratio is, the higher the efficacy of insulin action. Data are presented as mean \pm SEM. Statistical significance was set at $p<0.05$.

Data are reported as tAUC for subjective appetite and iAUC for blood glucose as recommended by Health Canada guidance documents and common usage. However, mean changes from baseline may be a more effective evaluation of the data. A treatment that has a high initial peak and then falls and a treatment that has a sustained blood glucose response 
may result in the same iAUC but may lead to a different and important observation when expressed as mean changes from baseline.

\section{Results}

\section{Participant Characteristics}

Thirty healthy men and women (sex: 14 males and 16 females; age $64.6 \pm 2.4$ years; BMI: $\left.25.6 \pm 2.5 \mathrm{~kg} / \mathrm{m}^{2}\right)$ completed all five sessions. Dropouts include three female participants and one male participant who were excluded due to high fasting blood glucose. Their results were not included in the analysis.

\section{Palatability of treatments}

Treatment had an effect on palatability scores $(\mathrm{p}<0.0001)$. Water was the least preferred compared to all other treatments which is likely due to it being served alone with no other food. There were no differences between other treatments.

\section{Food and Water Intake}

All treatments resulted in similar FI, cumulative energy intake, water intake and caloric compensation and were similarly undercompensated for at the later meal, averaging $63 \%$ (Table 2).

\section{Subjective Appetite}

Post-treatment (15-180 min) and cumulative (15-210 min) mean appetite changes from baseline were affected by time $(p<0.0001)$, treatment $(p<0.0001)$ and by a time-by-treatment interaction $(p<0.0001)$. All treatments equally suppressed appetite compared to water between 15-120 min $(p<0.0001$; Table 3$)$ but at 150 and 180 min milk was no longer different from 
water (Fig. 1). Over the entire post-treatment period, all treatments suppressed appetite compared to water but yogurt and cheese led to lower appetite than milk and soy beverage $(p<0.0001$; Table 3). However, tAUCs showed no differences between cheese, milk and soy beverage $(p<0.0001)$. There were no differences between treatments and control in the posttreatment period (Table 3). However, tAUCs showed all treatments led to lower appetite compared to water $(p<0.0001$; Table 4$)$.

An examination of the individual appetite scales (data not shown) showed that all treatments led to higher fullness than water and that yogurt led to higher fullness than milk in the posttreatment $(p<0.0001)$ and cumulative $(p<0.0001)$ periods. Post-meal, water and milk led to higher fullness than yogurt and soy beverage $(p=0.0002)$. Yogurt and cheese reduced hunger and DTE compared to water and milk in the post-treatment $(p<0.0001)$ and cumulative $(p<0.0001)$ periods. Post-meal, hunger was lower after water compared to all treatments except soy beverage $(p=0.0002)$ and DTE was lower after water compared to all treatments except milk $(p=0.0005)$. Cheese reduced PFC compared to water and milk in the posttreatment $(p<0.0001)$ and cumulative $(p<0.0001)$ periods. Post-meal, PFC was lower after water compared to yogurt and cheese $(p=0.006)$.

\section{Blood Glucose Concentrations}

Post-treatment (15-180 min) blood glucose mean changes from baseline were affected by time $(p<0.0001)$, treatment $(p<0.0001)$ and by a time-by-treatment interaction $(p=0.02)$. Blood glucose peaked at $45 \mathrm{~min}$ and returned to baseline by $180 \mathrm{~min}$ for all treatments (Fig. 2). Blood glucose was higher after soy beverage compared to yogurt from 30-90 min and higher compared to cheese from 60-120 min. Milk was not different from soy beverage and cheese from 30-60 min and not different from yogurt from 90-120 min. Over the entire post- 
treatment period, changes from baseline for blood glucose was equally lower for cheese and yogurt compared to soy beverage and milk ( $p<0.0001$; Table 3$)$. However, blood glucose iAUCs showed no differences between cheese and milk $(p<0.0001$; Table 4$)$. There were no differences between treatments in the post-meal period (210 min) (Table 3) for mean changes or iAUCs.

\section{Insulin Concentrations}

Insulin was measured in 12 participants (6 males, 6 females). Post-treatment (15-180 min) mean insulin changes from baseline were only affected by time $(p<0.0001)$. Insulin peaked at 30 and $45 \mathrm{~min}$ and returned to baseline by $180 \mathrm{~min}$ (Fig 3). There were no differences between any treatments at any time in the post-treatment or post-meal periods (Table 3). Similar results were observed with iAUCs (Table 4).

\section{Blood Glucose to Insulin Ratios}

In the post-treatment $(0-180 \mathrm{~min})$ period, the glucose/insulin iAUC ratio was highest for soy beverage compared to yogurt with no differences between any other treatments $(p=0.01$; Table 5). There were no differences between any treatments in the post-meal period (180-210 min) (Table 5). Cumulative (0-210 $\mathrm{min})$ results were the same as the post-treatment. When the ratios for mean changes from baseline at $30 \mathrm{~min}$ were considered, all treatments led to similar ratios (Table 5).

\section{Discussion}

The results support our hypothesis that, when consumed with glycemic carbohydrate, semisolid and solid dairy products increase satiety and decrease PPG more than liquid forms of dairy products or non-dairy beverages. Yogurt and cheese consumed with glycemic 
carbohydrate were more efficacious than milk or soy beverage at reducing appetite and PPG. However, the hypothesis that milk would be more effective than soy beverage was not supported.

This is the first study to report effects of dairy products on PPG, insulin, appetite and FI in older adults when consumed with a source of glycemic carbohydrate. Since there were no differences in insulin between any of the treatments, differences in blood glucose responses are likely due to insulin-independent mechanisms. Yogurt resulted in a low blood glucose peak and sustained blood glucose levels in the post-treatment period, suggesting delayed gastric emptying mediated by an increase in GI hormones due to protein as described in previous studies (Akhavan et al. 2014, Panahi et al. 2014). Additionally, Greek yogurt primarily contains casein which is known to clot and form a gel in the stomach and thereby delaying gastric emptying (Boirie et al. 1997). Although El Khoury et al. (El Khoury et al. 2014) did not detect a difference in blood glucose between Greek yogurts containing $23.1 \mathrm{~g}$, $22.2 \mathrm{~g}$ and $18.3 \mathrm{~g}$ of protein and skim milk containing $16.6 \mathrm{~g}$ of protein, the present results show lower blood glucose after breakfast, consistent with the high protein content of yogurt (17 g) compared with milk ( $9 \mathrm{~g})$. Evidence for insulin-independent mechanisms also arises from the lower blood glucose to insulin iAUC ratio after the yogurt breakfast compared to the soy beverage breakfast (Table 5). Since soy beverage led to similar ratios as cheese and milk, the higher efficacy of insulin at similar concentrations argues against attributing lower glucose concentrations to insulinotropic properties of milk proteins.

Breakfast meals were isocaloric to remove energy content as a confounder for detecting treatment differences on satiety. Subjective appetite ratings were affected not only by the protein content of the treatments but as well by food form. Although yogurt contained $10 \mathrm{~g}$ 
more protein than cheese, there were no differences in appetite between them. As previously described, delayed gastric emptying was only observed for yogurt and not cheese therefore a possible explanation in the lack of differences in appetite is the chewing requirements for each food arising from the differences in their food forms. Yogurt, a semi-solid with a gel-like consistency, was eaten with a spoon and required no chewing whereas cheese, a solid, required chewing before swallowing. A recent meta-analysis suggested that increasing chewing time of foods decreases self-reported hunger perhaps due to the stimulation of anorexigenic and the suppression of orexigenic gastrointestinal hormones (Miquel-Kergoat et al. 2015). In addition, cheese contained approximately three-fold the amount of fat, which is known to stimulate release of the satiety hormone, cholecystokinin (Beglinger and Degen 2004).

The semi-solid yogurt suppressed appetite more than milk but not soy beverage even though the latter were both fluids. While this observation may suggest that protein content was not a factor, an explanation for the appetite suppression following soy beverage may be its carrageenan content. Carrageenan is used as a thickening agent and $2.5 \mathrm{~g}$ added to milk has been shown to increase satiety (Arshad et al. 2016). However, the amount and type of carrageenan used in this soy beverage was not reported. Furthermore, the sweetness of the soy beverage may have contributed as sweetness increases satiety (Lavin et al. 2002). Cane sugar (sucrose) is the main sweetener used in this brand of soy beverage and has a sweetness factor of 1 whereas lactose has a sweetness factor of 0.22 relative to sucrose (Moskowitz 1970).

A second-meal effect of breakfast treatments was found on appetite but not on post-prandial glycemia. By 180 min, subjective appetite ratings had returned to baseline and were similar to the water control. However, following the ad libitum meal, appetite was lower after water 
than all treatments except milk. Since there were no differences in FI, this may be due to a more heightened sense of satiation after eating for the first time after an overnight fast.

However post-meal glycemia was not affected, again accounted for by similarities in FI at the meal.

The current study design fulfilled many of the fundamental criteria for satiety claims such as using a healthy adult population, a randomized crossover design, valid outcome measures, the recommended serving sizes of treatments and duration of time (Health Canada 2012).

Comparing the treatments in the context of a meal allowed for isocaloric breakfasts to be tested. If tested alone as usual serving sizes, the treatments could not follow Health Canada's guidelines as being equal to or lower than in energy than the reference food with the exception of the comparison made between the dairy products and soy beverage. However, since it was not a direct comparison of satiety response of the treatments alone but a comparison of their effect consumed with carbohydrate in a usual meal, the present study did not give rise to any satiety comparative claims amongst the treatments. However, compared with the soy beverage and milk, the yogurt and cheese breakfasts provided the greatest satiety and thus suggesting direct comparisons of them alone might allow a claim.

A further limitation of this study was the lack of control treatment for blood glucose as an outcome measure. An additional control of water consumed with bread and jam would have provided additional emphasis to the benefit of dairy on PPG when consumed with a carbohydrate versus consumption of carbohydrate foods (e.g. pastries, breads) alone at breakfast However, as noted, water alone was necessary to serve as the energy-free control as recommended for a satiety health claim (Health Canada 2012). Nevertheless, when treatment effects are compared using either soy beverage or milk as a control, yogurt and cheese 
resulted in lower PPG. The measurement of FI at 180 min, as suggested by HC, appears to be at a duration of time that is too late to be informative of the effect of small treatment effects. Our sample size calculations were based on effects found at $120 \mathrm{~min}$ but clearly needed to be larger than 30 participants to detect treatment differences of less than $10 \%$ at $180 \mathrm{~min}$ compared with that after the water control. Finally, since the study was conducted in healthy individuals, the results cannot be extrapolated to those who are obese, pre-diabetic or diabetic, for whom this type of research can ultimately benefit.

In conclusion, when consumed with glycemic carbohydrate at breakfast, cheese and yogurt increase satiety and lower PPG more than milk or a soy beverage.

\section{Acknowledgements}

We would like to thank all volunteers and research students who assisted in the conduction of sessions. This study was supported by a grant from the Dairy Research Cluster Initiative (Dairy Farmers of Canada, Agriculture and Agri-Food Canada, the Canadians Dairy Network and the Canadian Dairy Commission).

\section{References}

Akhavan, T. and Anderson, G. H. 2007. Effects of glucose-to-fructose ratios in solutions on subjective satiety, food intake, and satiety hormones in young men. Am. J. Clin. Nutr. 86(5): 1354-1363. PMID:17991646

Akhavan, T., Luhovyy, B. L. and Anderson, G. H. 2011. Effect of drinking compared with eating sugars or whey protein on short-term appetite and food intake. Int. J. Obes. (Lond.), 35(4): 562-569. doi:10.1038/ijo.2010.163. PMID:20733582. 
Akhavan, T., Luhovyy, B. L., Brown, P. H., Cho, C. E. and Anderson, G. H. 2010. Effect of premeal consumption of whey protein and its hydrolysate on food intake and postmeal glycemia and insulin responses in young adults. Am. J. Clin. Nutr. 91(4): 966-975. doi:10.3945/ajen.2009.28406. PMID:20164320.

Akhavan, T., Luhovyy, B. L., Panahi, S., Kubant, R., Brown, P. H. and Anderson, G. H. 2014. Mechanism of action of pre-meal consumption of whey protein on glycemic control in young adults. J. Nutr. Biochem. 25(1): 36-43. doi:10.1016/j.jnutbio.2013.08.012. PMID:24314863.

Almiron-Roig, E., Grathwohl, D., Green, H. and Erkner, A. 2009. Impact of some isoenergetic snacks on satiety and next meal intake in healthy adults. J. Hum. Nutr. Diet. 22(5): 469-474. doi:10.1111/j.1365-277X.2009.00978.x. PMID:19743984.

Arshad, M. U., Ishtiaq, S., Anjum, F. M., Saeed, F., Chatha, S. A. and Imran, A. 2016. Acute effects of different dietary polysaccharides added in milk on food intake, postprandial appetite and glycemic responses in healthy young females. Int J. Food Sci. Nutr. 67(6): 715-722. doi:10.1080/09637486.2016.1191446. PMID:27352777.

Beglinger, C. and Degen, L. 2004. Fat in the intestine as a regulator of appetite--role of CCK. Physiol. Behav. 83(4): 617-621. doi:10.1016/j.physbeh.2004.07.031. PMID:15621067. Boirie, Y., Dangin, M., Gachon, P., Vasson, M. P., Maubois, J. L. and Beaufrere, B. 1997. Slow and fast dietary proteins differently modulate postprandial protein accretion. Proc. Natl. Acad. Sci. USA, 94(26): 14930-14935. PMID:9405716.

Chapelot, D. and Payen, F. 2010. Comparison of the effects of a liquid yogurt and chocolate bars on satiety: a multidimensional approach. Br. J. Nutr. 103(5): 760-767. doi:10.1017/S000711450999225X. PMID:19874632.

Chollet, M., Gille, D., Piccinali, P., Butikofer, U., Schmid, A., Stoffers, H., et al. 2014. Short communication: dairy consumption among middle-aged and elderly adults in Switzerland. J. Dairy Sci. 97(9): 5387-5392. doi:10.3168/jds.2014-8193. PMID:24997665. 
Dougkas, A., Minihane, A. M., Givens, D. I., Reynolds, C. K. and Yaqoob, P. 2012.

Differential effects of dairy snacks on appetite, but not overall energy intake. Br. J. Nutr.

108(12): 2274-2285. doi:10.1017/S0007114512000323. PMID:22380537.

Dove, E. R., Hodgson, J. M., Puddey, I. B., Beilin, L. J., Lee, Y. P. and Mori, T. A. 2009.

Skim milk compared with a fruit drink acutely reduces appetite and energy intake in overweight men and women. Am. J. Clin. Nutr. 90(1): 70-75. doi:10.3945/ajcn.2008.27411. PMID:19474132.

El Khoury, D., Brown, P., Smith, G., Berengut, S., Panahi, S., Kubant, R., et al. 2014.

Increasing the protein to carbohydrate ratio in yogurts consumed as a snack reduces postconsumption glycemia independent of insulin. Clin. Nutr. 33(1): 29-38.

doi:10.1016/j.clnu.2013.03.010. PMID:23591152.

European Food Safety Authority. 2012. Guidance on the scientific requirements for health claims related to appetite ratings, weight management, and blood glucose concentrations. EFSA Journal, 10(3).

Foster-Powell, K., Holt, S. H. and Brand-Miller, J. C. 2002. International table of glycemic index and glycemic load values: 2002. Am. J. Clin. Nutr. 76(1): 5-56. PMID:12081815.

Government of Canada. 2013. Consumption of Dairy Products. Available from http://www.dairyinfo.gc.ca/index_e.php?s $1=$ dff-fcil\&s $2=$ cons\&s $3=$ conscdn $[$ accessed June 2016].

Health Canada. 2012. Draft Guidance Document - Satiety Health Claims on Food. Health Canada. 2013. Draft Guidance Document on Food Health Claims Related to the Reduction in Post-Prandial Glycaemic Response.

Herman, C. P. and Polivy, J. 1980. Restrained eating. Obesity, 208-225. 
Kirkman, M. S., Briscoe, V. J., Clark, N., Florez, H., Haas, L. B., Halter, J. B., et al. 2012. Diabetes in older adults. Diabetes Care, 35(12): 2650-2664. doi:10.1111/jgs. 12035. PMID:23106132.

Lavin, J. H., French, S. J. and Read, N. W. 2002. Comparison of oral and gastric administration of sucrose and maltose on gastric emptying rate and appetite. Int. J. Obes. Relat. Metab. Disord. 26(1): 80-86. doi:10.1038/sj.ijo.0801828. PMID: 11791150. Maersk, M., Belza, A., Holst, J. J., Fenger-Gron, M., Pedersen, S. B., Astrup, A., et al. 2012. Satiety scores and satiety hormone response after sucrose-sweetened soft drink compared with isocaloric semi-skimmed milk and with non-caloric soft drink: a controlled trial. Eur. J. Clin. Nutr. 66(4): 523-529. doi:10.1038/ejcn.2011.223. PMID:22252107.

Mehrabani, S., Safavi, S. M., Mehrabani, S., Asemi, M., Feizi, A., Bellissimo, N., et al. 2016. Effects of low-fat milk consumption at breakfast on satiety and short-term energy intake in 10- to 12-year-old obese boys. Eur. J. Nutr. 55(4): 1389-1396. doi:10.1007/s00394-015-0956-

\section{PMID:26099369.}

Mintel. 2016. US Sales of Dairy Milk Turn Sour as Non-Dairy Milk Sales Grow 9\% in 2015. Available from http://www.mintel.com/press-centre/food-and-drink/us-sales-of-dairy-milkturn-sour-as-non-dairy-milk-sales-grow-9-in-2015 [accessed June 2016].

Miquel-Kergoat, S., Azais-Braesco, V., Burton-Freeman, B. and Hetherington, M. M. 2015. Effects of chewing on appetite, food intake and gut hormones: A systematic review and metaanalysis. Physiol. Behav. 151: 88-96. doi:10.1016/j.physbeh.2015.07.017. PMID:26188140. Moskowitz, H. R. 1970. Ratio scales of sugar sweetness. Perception \& Psychophysics, 7(5): 315-320. PMID:8670711.

Onvani, S., Haghighatdoost, F., Surkan, P. J. and Azadbakht, L. 2016. Dairy products, satiety and food intake: A meta-analysis of clinical trials. Clin. Nutr. 36(2): 389-398.

doi:10.1016/j.clnu.2016.01.017. PMID: 26923518 
Panahi, S., El Khoury, D., Kubant, R., Akhavan, T., Luhovyy, B. L., Goff, H. D., et al. 2014. Mechanism of action of whole milk and its components on glycemic control in healthy young men. J. Nutr. Biochem. 25(11): 1124-1131. doi:10.1016/j.jnutbio.2014.07.002. PMID:25167977.

Panahi, S., El Khoury, D., Luhovyy, B. L., Goff, H. D. and Anderson, G. H. 2013. Caloric beverages consumed freely at meal-time add calories to an ad libitum meal. Appetite, 65: 7582. doi:10.1016/j.appet.2013.01.023. PMID:23402713.

Panahi, S., Luhovyy, B. L., Liu, T. T., Akhavan, T., El Khoury, D., Goff, H. D., et al. 2013. Energy and macronutrient content of familiar beverages interact with pre-meal intervals to determine later food intake, appetite and glycemic response in young adults. Appetite, $\mathbf{6 0}(1)$ : 154-161. doi:10.1016/j.appet.2012.09.018. PMID:23022554.

Pasin, G. and Comerford, K. B. 2015. Dairy foods and dairy proteins in the management of type 2 diabetes: a systematic review of the clinical evidence. Adv. Nutr. 6(3): 245-259. doi:10.3945/an.114.007690. PMID:25979490.

Patel, B. P., Luhovyy, B., Mollard, R., Painter, J. E. and Anderson, G. H. 2013. A premeal snack of raisins decreases mealtime food intake more than grapes in young children. Appl. Physiol. Nutr. Metab. 38(4): 382-389. doi:10.1139/apnm-2012-0309. PMID:23713530. Sebastian, R. S., Goldman, J. D., Enns, C. W. and LaComb, R. P. (2010). Fluid Milk Consumption in the United States, USDA. Statistics Canada. 2006. Findings from the Canadian Community Health Survey - Overview of Canadians' Eating Habits. Available from http://www5.statcan.gc.ca/olc$\underline{\text { cel/olc.action?ObjId=82-620-M2006002\&ObjType }=46 \& \text { lang }=\text { en } \& \text { limit }=0}$ [accessed June $2016]$. 
Sun, L., Tan, K. W., Han, C. M., Leow, M. K. and Henry, C. J. 2015. Impact of preloading either dairy or soy milk on postprandial glycemia, insulinemia and gastric emptying in healthy adults. Eur. J. Nutr. doi:10.1007/s00394-015-1059-y. PMID:26439722.

Tsuchiya, A., Almiron-Roig, E., Lluch, A., Guyonnet, D. and Drewnowski, A. 2006. Higher satiety ratings following yogurt consumption relative to fruit drink or dairy fruit drink. J. Am. Diet. Assoc. 106(4): 550-557. doi:10.1016/j.jada.2006.01.004. PMID:16567151.

Vuguin, P., Saenger, P. and Dimartino-Nardi, J. 2001. Fasting glucose insulin ratio: a useful measure of insulin resistance in girls with premature adrenarche. J. Clin. Endocrinol. Metab. 86(10): 4618-4621. doi:10.1210/jcem.86.10.7956. PMID:11600513. 
Table 1. Nutritional composition of treatments and breakfast foods

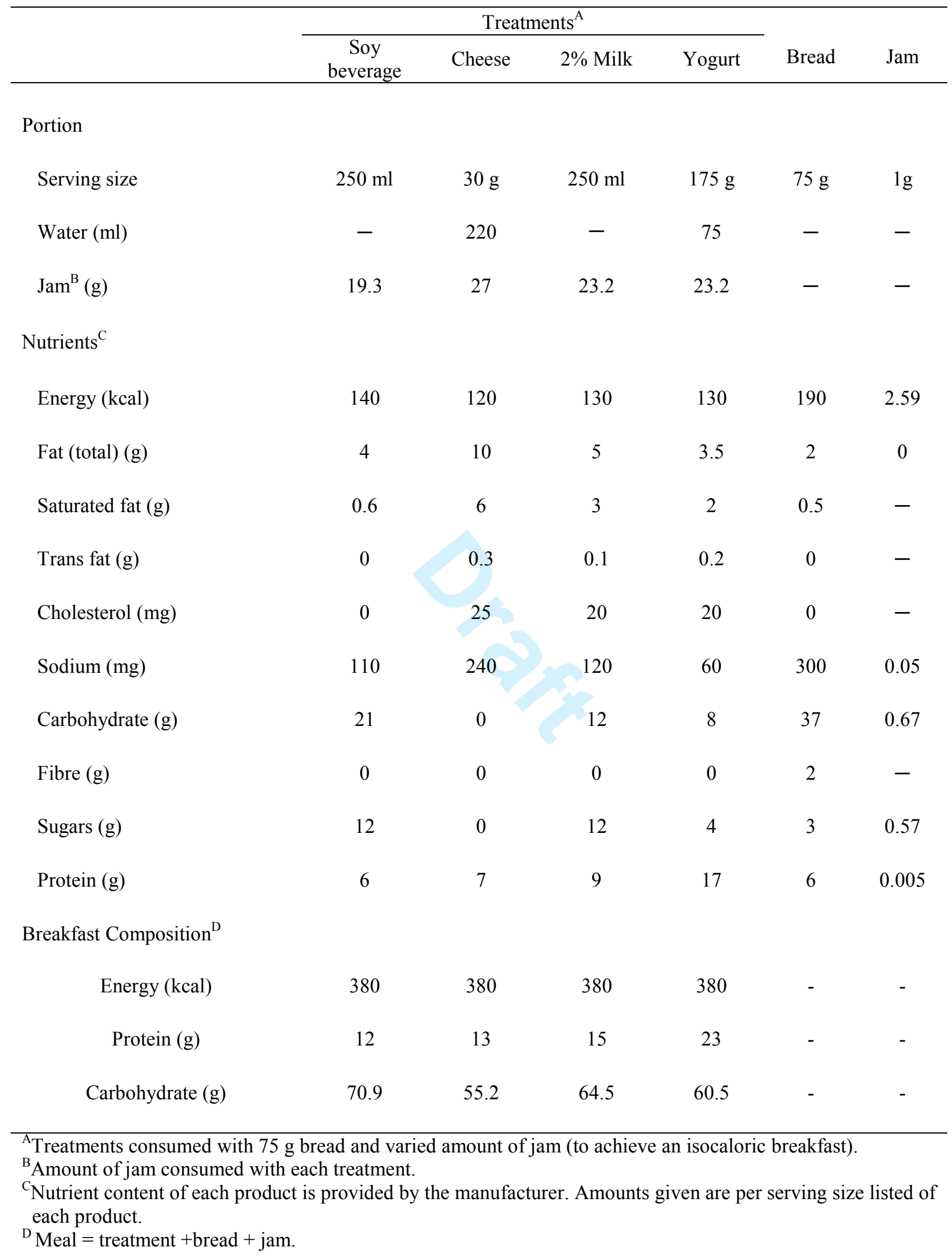


Table 2. Energy intake, cumulative energy intake, water intake and caloric compensation $^{\mathrm{A}}$

\begin{tabular}{|c|c|c|c|c|}
\hline \multirow[t]{2}{*}{ Treatment } & \multicolumn{2}{|c|}{ Energy intake (kCal) } & \multirow{2}{*}{$\begin{array}{c}\text { Water Intake } \\
(\mathrm{g})\end{array}$} & \multirow{2}{*}{$\begin{array}{c}\text { Caloric } \\
\text { Compensation }(\%)^{\mathrm{D}}\end{array}$} \\
\hline & Test meal $^{\mathrm{B}}$ & Cumulative $^{\mathrm{C}}$ & & \\
\hline Control $^{\mathrm{E}}$ & $867.9 \pm 57.2$ & $867.9 \pm 57.2$ & $352.3 \pm 29.7$ & - \\
\hline Soy beverage & $792.4 \pm 53.1$ & $1172.4 \pm 53.1$ & $385.1 \pm 27.0$ & $54.0 \pm 22.9$ \\
\hline Cheese & $760.6 \pm 54.4$ & $1140.6 \pm 54.4$ & $377.5 \pm 27.7$ & $82.6 \pm 36.5$ \\
\hline $2 \%$ Milk & $802.0 \pm 49.3$ & $1182.0 \pm 49.3$ & $370.0 \pm 24.3$ & $54.9 \pm 30.5$ \\
\hline Yogurt & $789.3 \pm 61.8$ & $1169.3 \pm 61.8$ & $395.2 \pm 22.9$ & $60.5 \pm 31.9$ \\
\hline$p$ & NS & NS & NS & NS \\
\hline $\begin{array}{l}{ }^{\mathrm{A}} \text { All values are } \\
\text { ANOVA via } \mathrm{p} \\
{ }^{\mathrm{B}} \text { Energy consu } \\
\text { consumption. } \\
{ }^{\mathrm{C}} \text { Energy in bre } \\
{ }^{\mathrm{D}} \text { Caloric comp } \\
\text { consumed at th } \\
{ }^{\mathrm{E}} \text { Water }(250 \mathrm{~m}\end{array}$ & $\begin{array}{l}\text { means } \pm \text { SEN } \\
\text { oc mixed pro } \\
\text { med in an ad } 1 \\
\text { kffast meal }(\mathrm{t} 1 \\
\text { ensation }=[(\mathrm{k} \\
\text { e meal after tl }\end{array}$ & $\begin{array}{l}\text { s }(n=30) \cdot p< \\
\text { edure, Tukey's } \\
\text { oitum meal wa } \\
\text { atment }+ \text { breac } \\
\text { al consumed at } \\
\text { treatment }) / k c\end{array}$ & $\begin{array}{l}5 \text { (treatment eft } \\
\text { st-hoc). } \\
\text { easured at } 180 \\
\text { jam) + energy } \\
\text { eal after the wat }\end{array}$ & $\begin{array}{l}\text { using one-way } \\
\text { following treatment } \\
\text { m meal. } \\
\text { control - kcal } \\
100 .\end{array}$ \\
\hline
\end{tabular}


Table 3. Effect of treatment on post-treatment, post-meal and cumulative mean changes from baseline for subjective appetite, blood glucose and insulin ${ }^{\mathrm{A}}$

\begin{tabular}{|c|c|c|c|c|c|c|c|}
\hline & & Control $^{\mathrm{B}}$ & $\begin{array}{c}\text { Soy } \\
\text { beverage }\end{array}$ & Cheese & 2\% Milk & Yogurt & $p$ \\
\hline \multirow[t]{3}{*}{ Appetite (mm) } & Post-treatment ${ }^{\mathrm{C}}$ & $3.9 \pm 0.8^{\mathrm{a}}$ & $-22.2 \pm 1.7^{\mathrm{b}}$ & $-23.8 \pm 1.8^{\mathrm{c}}$ & $-18.1 \pm 1.7^{b}$ & $-25.2 \pm 1.9^{c}$ & $<0.0001$ \\
\hline & Post-meal $^{\mathrm{D}}$ & $-61.7 \pm 4.7$ & $-48.1 \pm 4.9$ & $-44.5 \pm 5.3$ & $-52.5 \pm 5.0$ & $-44.1 \pm 4.8$ & NS \\
\hline & Cumulative $^{\mathrm{E}}$ & $-2.2 \pm 1.4^{\mathrm{a}}$ & $-25.5 \pm 1.7^{\mathrm{b}}$ & $-26.5 \pm 1.8^{\mathrm{c}}$ & $-22.0 \pm 1.8^{\mathrm{b}}$ & $-27.9 \pm 1.8^{\mathrm{c}}$ & $<0.0001$ \\
\hline \multirow[t]{3}{*}{ Glucose (mmol/L) } & Post-treatment & - & $1.6 \pm 0.1^{\mathrm{a}}$ & $1.2 \pm 0.1^{\mathrm{b}}$ & $1.4+0.1^{\mathrm{a}}$ & $1.1 \pm 0.08^{\mathrm{b}}$ & $<0.0001$ \\
\hline & Post-meal & - & $1.7 \pm 0.2$ & $1.5 \pm 0.2$ & $1.5 \pm 0.2$ & $1.6 \pm 0.2$ & NS \\
\hline & Cumulative & - & $1.6 \pm 0.1^{\mathrm{a}}$ & $1.2 \pm 0.09^{\mathrm{b}}$ & $1.4 \pm 0.09^{\mathrm{a}}$ & $1.1 \pm 0.08^{\mathrm{b}}$ & $<0.0001$ \\
\hline \multirow[t]{3}{*}{ Insulin $(\mu \mathrm{U} / \mathrm{ml})$} & Post-treatment & - & $31.1 \pm 4.2$ & $27.3 \pm 3.9$ & $32.3 \pm 4.6$ & $34.8+4.4$ & NS \\
\hline & Post-meal & - & $46.8 \pm 8.2$ & $41.3 \pm 7.3$ & $49.2 \pm 10.3$ & $36.8 \pm 7.7$ & NS \\
\hline & Cumulative & - & $31.2 \pm 4.2$ & $27.3 \pm 3.9$ & $32.3 \pm 4.6$ & $34.8 \pm 4.4$ & NS \\
\hline
\end{tabular}

\footnotetext{
${ }^{\mathrm{A}}$ All values are means \pm SEMs (appetite and glucose: $n=30$; insulin: $n=12$ ). Means within a row with different superscript letters are significantly different, $p<0.05$ (treatment effect using two-way ANCOVA via proc mixed procedure, Tukey's post hoc).

${ }^{\mathrm{B}}$ Water $(250 \mathrm{~mL})$.

${ }^{\mathrm{C}}$ Post-treatment values are mean changes from baseline of all observations before the test meal: 15, 30, 45, 60, 90, 120, 150 and 180 min for appetite and glucose and 30, 60, 90, 120, 150 and 180 min for insulin.

Dost-meal values are mean changes from baseline of all observations after the test meal: $210 \mathrm{~min}$.

${ }^{\mathrm{E}}$ Cumulative values are mean changes from baseline for all observations for the entire session: 15-210 min.
} 
Table 4. Effect of treatment on post-treatment, post-meal and cumulative tAUCs for subjective appetite and iAUCs for blood glucose and insulin ${ }^{\mathrm{A}}$
Control $^{\mathrm{B}} \quad$ Soy
Soy

Appe

(mm $\min )$
Post-treatment $^{\mathrm{C}}$

Pos

Post-meal $^{\mathrm{D}}$

$$
\text { Cumulative }^{\mathrm{E}}
$$

1470$$
1457.3+72.6^{\mathrm{b}}
$$$$
8678.5+592.1^{\mathrm{ab}} \quad 7902.8+578.1^{\mathrm{ab}}
$$

$9307.0 \pm 584.3^{\mathrm{b}}$

$7652.6+656.1^{\mathrm{a}} \quad<.0001$

$1457.3+72.6^{\mathrm{b}}$

$1200.0+78.9^{\mathrm{a}}$

$1080.3+88.7^{\mathrm{a}}$

$1180.5 \pm 83.7^{\mathrm{a}}$

$1121.0+78.4^{\mathrm{a}} \quad<.0001$

$$
14703.0 \pm 480.9^{\mathrm{c}}
$$$$
9918.6 \pm 654.5^{\mathrm{ab}}
$$

$9022.0 \pm 632.4^{\mathrm{ab}}$

$10494.8 \pm 616.2^{\mathrm{b}}$

$8791.2 \pm 722.6^{\mathrm{a}} \quad<.0001$

Glucose

$$
\text { Post-treatment }
$$

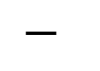

$$
279.2 \pm 29.5^{\mathrm{a}}
$$$$
216.4 \pm 26.0^{\text {bc }}
$$$$
250.0 \pm 24.8^{\mathrm{ab}}
$$$$
200.1 \pm 21.7^{\mathrm{c}}
$$$$
<.0001
$$

(mmol

$\min / \mathrm{L})$

$$
\text { Post-meal }
$$$$
\begin{array}{ll}
- & 25.9 \pm 2.7
\end{array}
$$

Cumulative

$-$

$-$

Post-treatment

Post-meal

Cumulative$$
302.0+33.3^{\mathrm{a}}
$$

$6631.3 \pm 874.6$

$467.5+81.9$

$$
23.2 \pm 3.1
$$

$231.7 \pm 28.3^{\mathrm{b}}$

$5708.7 \pm 918.6$

$412.3+80.0$

$6892.8+901.7$

$$
23.1 \pm 2.1
$$

$266.3 \pm 25.5^{\mathrm{ab}}$

$6916.8 \pm 987.1$

$491.9 \pm 103.3$

$$
24.5 \pm 2.6
$$

NS

$$
220.9 \pm 22.3^{\mathrm{b}} \quad<.0001
$$

$7244.2 \pm 801.9 \quad$ NS

$378.7 \pm 70.9 \quad$ NS

\footnotetext{
${ }^{\mathrm{A}}$ All values are mea
superscript letters
hoc).
${ }^{\mathrm{B}}$ Water $(250 \mathrm{~mL})$.

${ }^{C}$ Post-treatment values are AUCs of all observations before the test meal: 0, 15, 30, 45, 60, 75, 90, 120, 150 and 180 min. for appetite and glucose and 0,30, 60,90,120,150 and 180 min for insulin.

${ }^{D}$ Post-meal values are mean changes from baseline of all observations after the test meal: $210 \mathrm{~min}$.

${ }^{\mathrm{E}}$ Cumulative values are AUCs for all observations for the entire session: 0-210 min.
} 
Table 5. Effect of treatment on post-treatment, post-meal and cumulative ratios of blood glucose to insulin iAUC and on ratios of blood glucose to insulin changes from baseline at $30 \mathrm{~min}^{\mathrm{A}}$

\begin{tabular}{|c|c|c|c|c|c|c|}
\hline & & $\begin{array}{c}\text { Soy } \\
\text { beverage }\end{array}$ & Cheese & 2\% Milk & Yogurt & $p$ \\
\hline \multirow{3}{*}{ 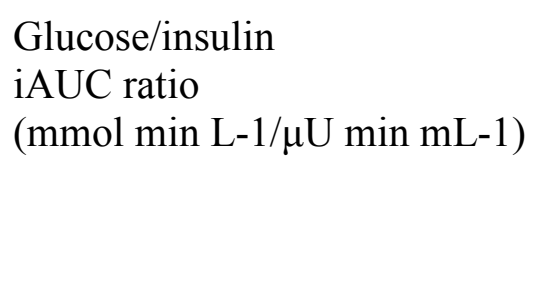 } & Post-treatment $^{\mathrm{B}}$ & $0.06+0.01^{\mathrm{a}}$ & $0.05+0.01^{\mathrm{ab}}$ & $0.05+0.01^{\mathrm{ab}}$ & $0.04+0.005^{\mathrm{b}}$ & 0.01 \\
\hline & Post-meal ${ }^{\mathrm{C}}$ & $0.08+0.02$ & $0.08+0.02$ & $0.07+0.01$ & $0.09+0.02$ & NS \\
\hline & Cumulative $^{\mathrm{D}}$ & $0.06+0.01^{\mathrm{a}}$ & $0.06+0.01^{\mathrm{ab}}$ & $0.06+0.01^{\mathrm{ab}}$ & $0.04+0.004^{\mathrm{b}}$ & 0.02 \\
\hline $\begin{array}{l}\text { Glucose/insulin } \\
\text { changes from baseline ratio } \\
(\mathrm{mmol} \min \mathrm{L}-1 / \mu \mathrm{U} \text { min } \mathrm{mL}-1)\end{array}$ & $30 \mathrm{~min}$ & $0.1+0.02$ & $0.2+0.04$ & $0.2+0.03$ & $0.1+0.02$ & NS \\
\hline
\end{tabular}

\footnotetext{
${ }^{\mathrm{A}}$ All values are means \pm SEMs $(n=12)$. Means within a row with different superscript letters are significantly different, $p<0.05$ (treatment using one-way ANOVA via proc mixed procedure, Tukey's post hoc).

${ }^{\mathrm{B}}$ Post-treatment values are mean changes from baseline of all observations before the test meal: $0,15,30,45,60$, 90,120,150 and $180 \mathrm{~min}$ for appetite and glucose and 0,30,60,90,120,150 and $180 \mathrm{~min}$ for insulin.

${ }^{\mathrm{C}}$ Post-meal values are mean changes from baseline of all observations after the test meal: $210 \mathrm{~min}$.

${ }^{\mathrm{D}} \mathrm{Cumulative} \mathrm{values} \mathrm{are} \mathrm{mean} \mathrm{changes} \mathrm{from} \mathrm{baseline} \mathrm{for} \mathrm{all} \mathrm{observations} \mathrm{for} \mathrm{the} \mathrm{entire} \mathrm{session:} \mathrm{0-210} \mathrm{min.}$
} 


\section{Figure Captions}

Figure 1. Effect of treatments on average subjective appetite mean changes from baseline over time. Means with different superscripts are significantly different at each measured time (one-way ANOVA, Tukey-Kramer post-hoc test, $p<0.05)$. All values are mean $\pm \operatorname{SEM}(n=$ $30)$.

Figure 2. Effect of treatments on blood glucose mean changes from baseline over time.

Means with different superscripts are significantly different at each measured time (one-way ANOVA, Tukey-Kramer post-hoc test, $p<0.05)$. All values are mean $\pm \operatorname{SEM}(n=30)$.

Figure 3. Effect of treatments on insulin mean changes from baseline over time. Means with different superscripts are significantly different at each measured time (one-way ANOVA, Tukey-Kramer post-hoc test, $p<0.05)$. All values are mean $\pm \operatorname{SEM}(n=12)$. 


\section{Figure 1}

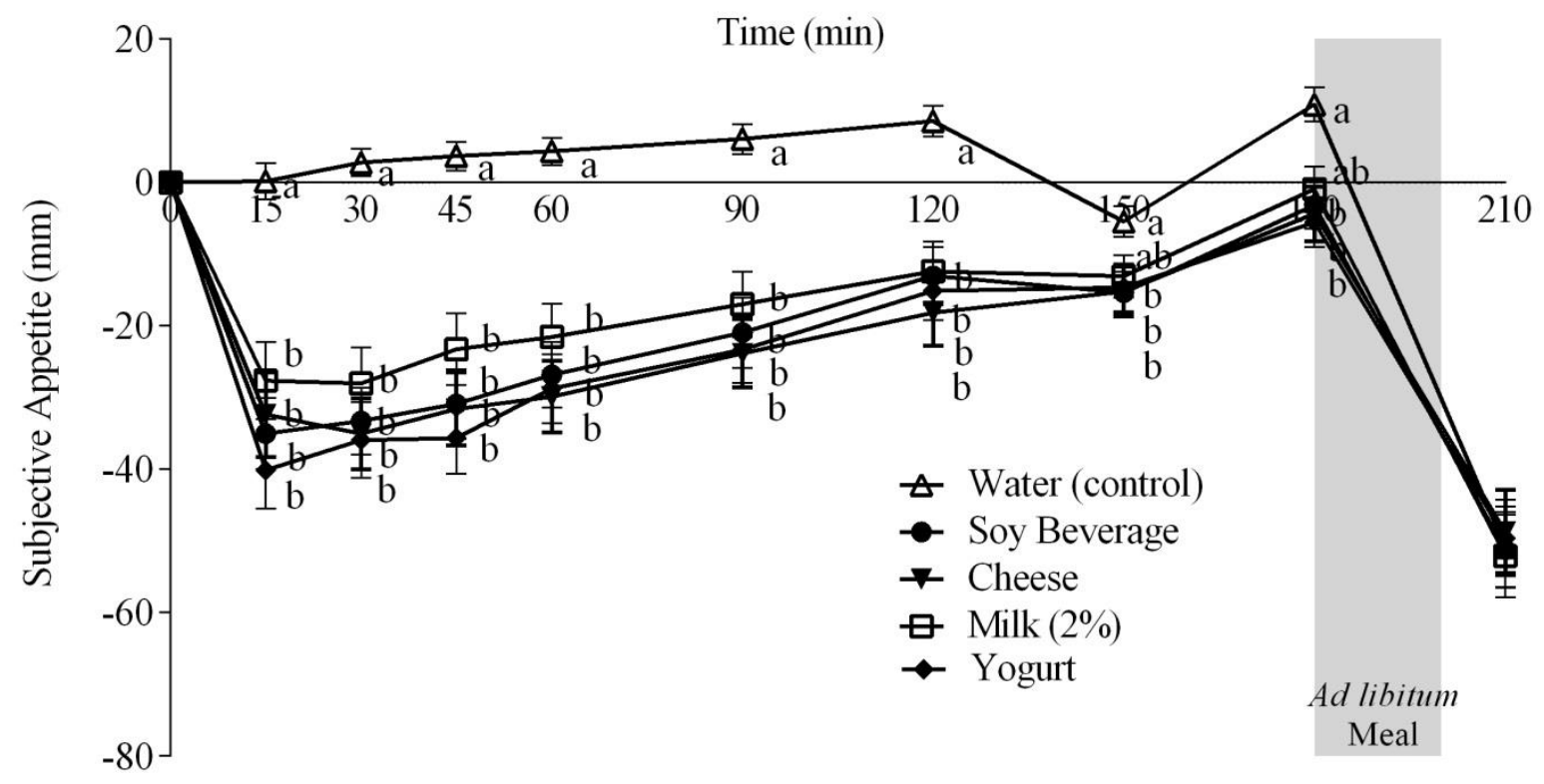


Figure 2

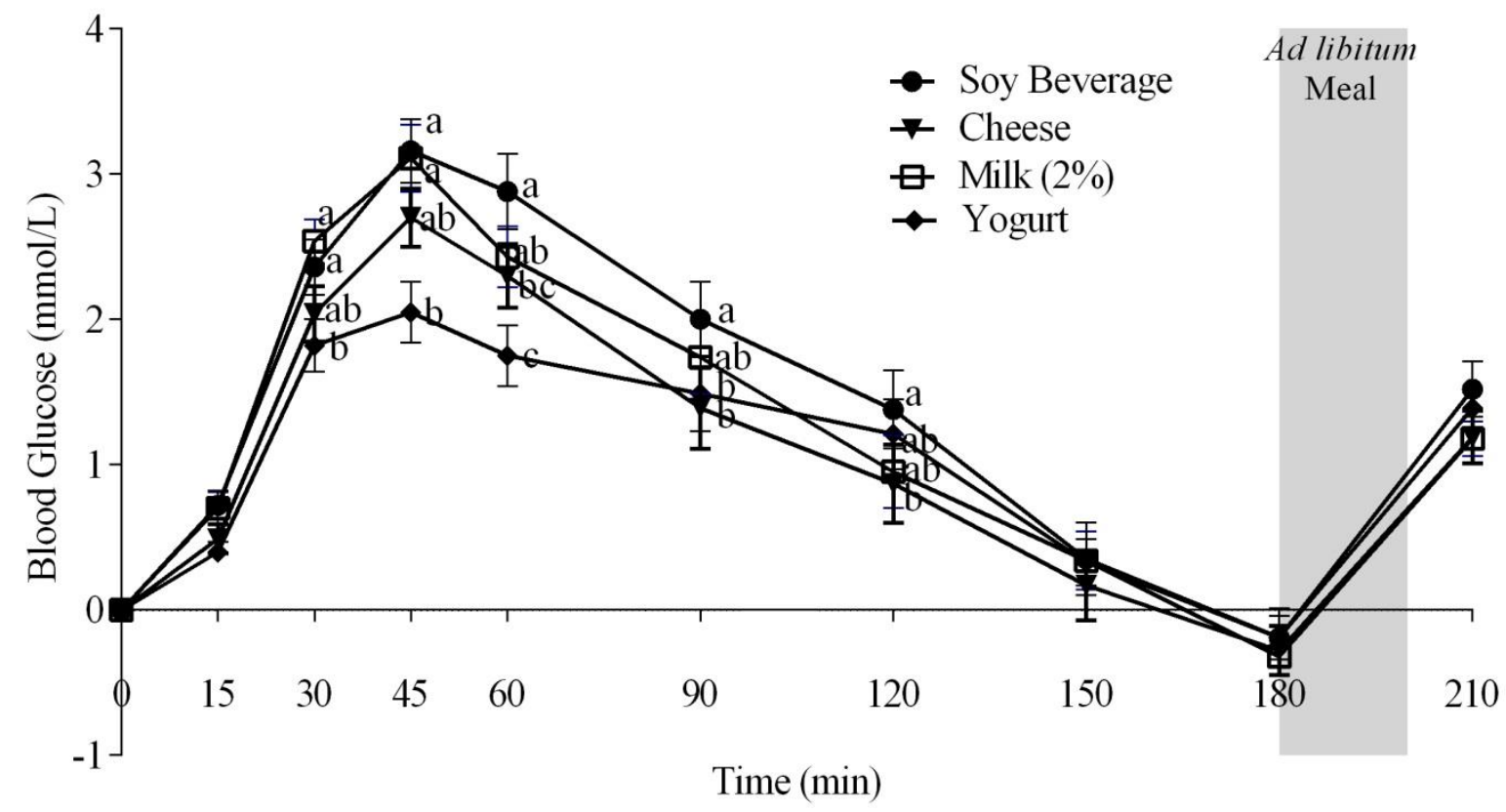


Figure 3

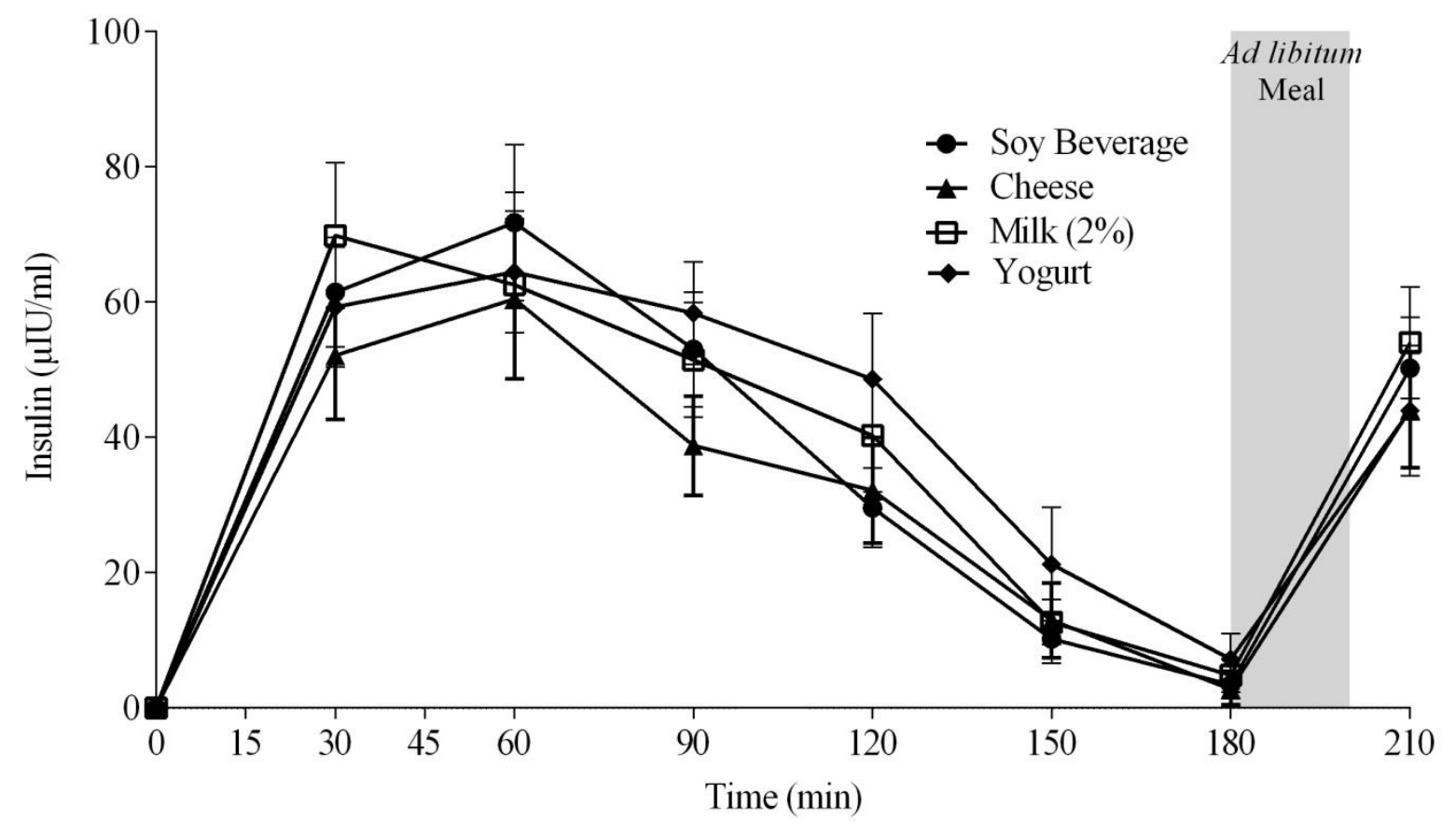

